\title{
Seguimiento a largo plazo del soporte uretral tendinoso: un enfoque anatómico para incontinencia urinaria de esfuerzo
}

\author{
Palma P, Riccetto C, Fraga R, Martins M, Reges R, de Oliveira M, Rodrigues Netto N Jr. \\ División de Urología Feminina, Universidad Estadual de Campinas, UNICAMP, Campinas, Sao Paulo, Brasil.
}

Actas Urol Esp. 2007;31(7):759-763

\section{RESUMEN}

\section{SEGUIMIENTO A LARGO PLAZO DEL SOPORTE URETRAL TENDINOSO: UN ENFOQUE ANATÓMICO PARA INCONTINENCIA URINARIA DE ESFUERZO}

Los procedimientos tipo sling han sido utilizados por décadas para el manejo de la incontinencia urinaria de esfuerzo (IUE) femenina, pero sólo en la década pasada han llegado a ser la técnica de elección. Los procedimientos mínimamente invasivos son el procedimiento de elección en algunos centros por su eficacia y baja morbilidad. El soporte uretral tendinoso (TUS) representa un enfoque anatómico que consiste en colocar una cincha de baja tensión a nivel de la uretra media, anclada al arco tendíneo de manera bilateral. De febrero 1999 a octubre 2000, 25 pacientes femeninas con IUE y con una edad media de 53 años fueron intervenidas mediante TUS. De ellas, 23 pudieron evaluarse a largo plazo con un seguimiento un máximo 72 meses. Después de 6 meses, 20 pacientes $(87 \%)$ se encontraban secas, $2(8,7 \%)$ mejoraron y $1(4,3 \%)$ era incontinente. Sin embargo, al final del seguimiento, 15 pacientes estaban continentes $(65,2 \%), 3(13 \%)$ mejoraron y $5(21 \%)$ seguían incontinentes. Por lo que, el TUS es un concepto que merece investigaciones adicionales.

Palabras clave: Incontinencia urinaria de esfuerzo. Sling minimamente invasivo. Soporte uretral tendinoso. Submucosa de intestino delgado.

\section{ABSTRACT \\ LONG TERM FOLLOW-UP OF THE TENDINOUS URETHRAL SUPPORT: AN ANATOMICAL APPROACH FOR STRESS URINARY INCONTINENCE}

Sling procedures have been around for decades in the management female stress urinary incontinence (SUI), but only in the past decade they have become the preferred technique. Minimally invasive procedures are the procedure of choice in many centers for your efficacy and low morbidity. The tendinous urethral support (TUS) represents an anatomical approach that consists in placing a midurethral low tension tape anchored to the tendinous arc bilaterally. From February 1999 to October 2000, 25 female patients (mean age: 53 years old), with SUI underwent TUS procedure, and 23 were available for follow-up. Those patients were followed until 72 months. After six months, $20(87 \%)$ patients were dry, 2 (8.7\%) improved and 1 (4.3\%) incontinent. However, at the last evaluation, $15(65.2 \%)$ vestigation.

Keywords: Stress urinary incontinence. Minimally invasive sling. Tendinous urethral support. Small intestine submucosa.

$\mathrm{L}$ a comprensión de los conceptos fisiopatológícos de la incontinencia urinaria de esfuerzo (IUE) ha mejorado consistentemente en la última década y sus aplicaciones han llevado al desarrollo de algunas técnicas quirúrgicas.
Basados en la teoría integral, Pétros y Ulstem propusieron la cincha vaginal libre de tensión (TVT). Esta teoría plantea que una cincha en la uretra media puede estabilizar la uretra durante el esfuerzo sin modificar la movilidad cervico uretral ${ }^{1,2}$. 
A pesar de una buena tasa de cura reportada con TVT, se han descrito complicaciones mayores como lesiones intestinales y de vasos sanguíneos mayores ${ }^{3}$. Muchas de las complicaciones descritas se relacionan con la naturaleza ciega de estos procedimientos. Para evitar estas complicaciones, se desarrollaron abordajes alternativos usando la vía prepúbica o transobturatriz (TOT) ${ }^{4,5}$. La tasa de continencia con el abordaje TOT ha sido similar al obtenido con el abordaje transvaginal retropubico ${ }^{6}$.

El objetivo de este trabajo es presentar nuestros datos a largo plazo usando el soporte uretral tendinoso (TUS), un procedimiento mínimamente invasivo para restaurar el soporte uretral.

\section{MATERIALES Y METODOS}

\section{Muestra}

Se realizó un estudio clínico prospectivo, abierto, reclutando pacientes con IUE urodinámicamente confirmada. Este estudio fue aprobado por nuestro comité de ética. De febrero 1999 a octubre 2000, se llevo a cabo el procedimiento TUS usando submucosa de intestino delgado de porcino SIS a 25 mujeres con IUE. La edad media fue 53 años (rango 30-77). Todas las pacientes fueron evaluadas con historia clínica, examen físico, test de esfuerzo, pad test de 1 hora estandarizado, y estudio urodinámico. El estudio urodinámico se realizó con dos catéteres uretrales. Uno de 8 fr para llenado y otro 6 fr para registro de presión vesical. Además de un catéter rectal para registrar presión abdominal. Durante el seguimiento, las pacientes fueron revisadas a los 1, 3 y 6 meses después de la cirugía y, a partir de entonces, cada año. Durante el seguimiento, en cada visita las pacientes fueron interrogadas sobre su continencia urinaria, síntomas del tracto urinario inferior y presencia de dispareunia. $\mathrm{El}$ pad test se utilizó para evaluar objetivamente el resultado de la cirugía. Se consideró a una paciente curada si se encontraba completamente seca durante el seguimiento. Se consideró mejorada, si presentaban un 50\% o más de disminución del peso de la compresa. El resto de los resultados fue considerado como fallo.

\section{Técnica quirúrgica}

El procedimiento se llevó a cabo con la paciente en posición de litotomía bajo anestesia espinal.
Como profilaxis antimicrobiana, se administraron $2 \mathrm{~g}$ de cefalosporina de primera generación por vía endovenosa durante el tiempo de inducción anestésica. Se realizó una incisión vaginal vertical de $5 \mathrm{~cm}$ a $1,29 \mathrm{~cm}$ del meato uretral. Mediante una disección vaginal mínima lateral hacia la rama ascendente del hueso isquiopúbico, se perforó la fascia endopélvica bilateralmente hasta el arco tendíneo (Fig. 1). Posteriormente, se colocaron dos suturas de polipropileno 2-0 en la línea blanca a ambos lados. Luego, una cinta de SIS de $25 \mathrm{~cm}$ se fijó al arco tendíneo de un lado y se recortó para fijarla al lado opuesto. De esta forma, se creó una hamaca suburetral de baja tensión (Figs. 2 y 3). Finalmente, se cerró la pared vaginal de manera usual, no se hizo cistoscopia después de la cirugía y se dejó catéter vesical tipo Foley 16 fr. La paciente fue dada de alta después tras retirar el catéter y comprobar que el volumen residual era inferior a $100 \mathrm{ml}$.

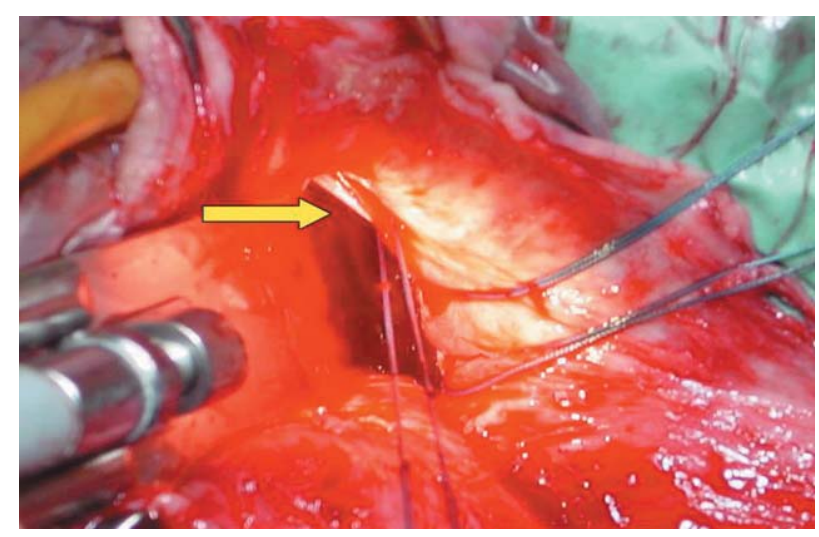

FIGURA 1. Nótese la sutura colocada en el arco tendineo (linea blanca).

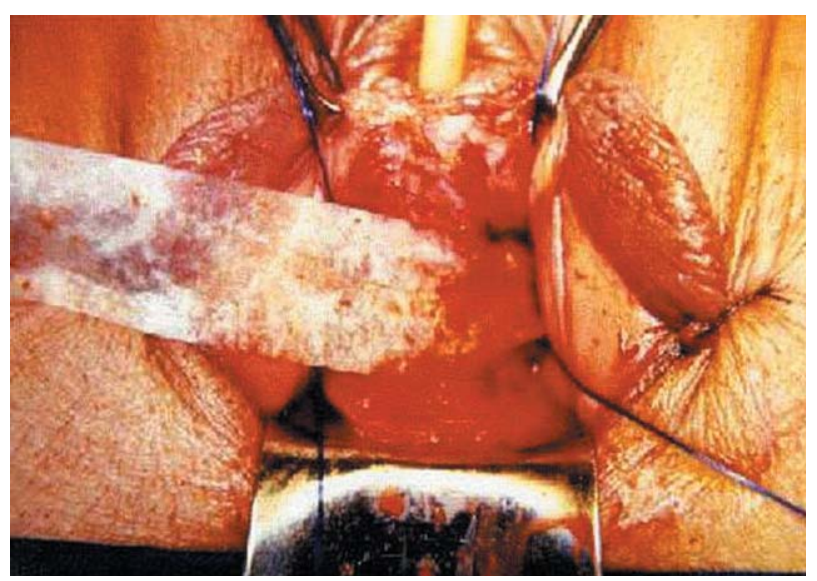

FIGURA 2. La cinta SIS es suturada a un lado de la linea blanca. 


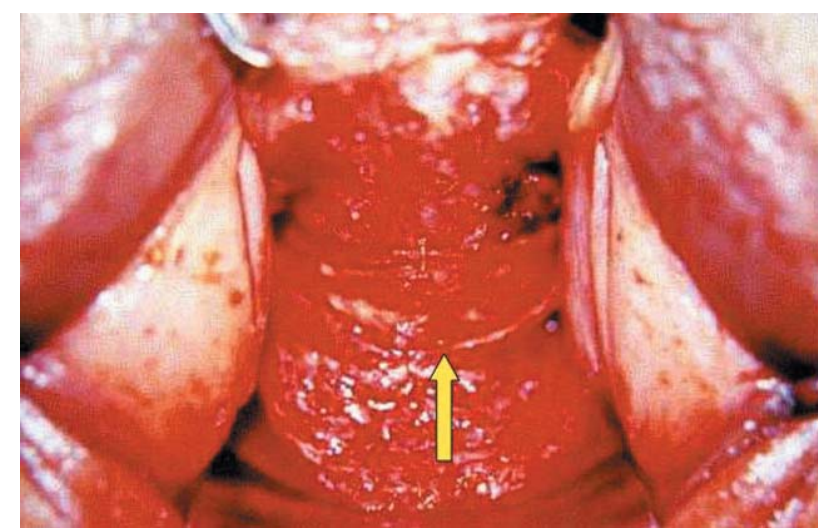

FIGURA 3. Aspecto final del soporte uretral tendinoso.

\section{RESULTADOS}

Los datos demográficos de todas las pacientes son mostrados en la Tabla 1. El examen físico determino un compartimiento vaginal anterior y posterior adecuado y ninguna mujer tuvo prolapso de órganos pélvicos significativo. El test de esfuerzo fue positivo en todas las pacientes y el peso del pad test preoperatorio medio fue $70 \mathrm{~g}$ (rango 10-150).

Tabla 1. Características demográficas de las 23 pacientes intervenidas.

\begin{tabular}{lr}
\hline Variable & \\
\hline Edad, años (rango) & $52(30-77)$ \\
Paridad, número (rango) & $2(0-15)$ \\
Enfermedades asociadas, número (\%) & $12(52,17)$ \\
Operación vaginal previa, número (\%) & $20(87)$ \\
Urgencia preoperatorio, número (\%) & $2(8,7)$ \\
\hline
\end{tabular}

La presión abdominal de fuga (VLPP) media fue de $76 \mathrm{~cm}$ de agua (rango 20-150). Si bien, en 10 pacientes $(43,4 \%)$ el VLPP era superior a 90 cm de $\mathrm{H}_{2} \mathrm{O}$ (media=98 y rango 95-115) y en 13 $(56,52 \%)$ se encontraba por debajo de $90 \mathrm{~cm}$ de $\mathrm{H}_{2} \mathrm{O}$ (media $=57$ y rango 38-90. En el estudio urodinámico no se demostró que ninguna paciente tuviera hiperactividad del detrusor.

Un total de 20 pacientes $(86,9 \%)$ presentaban antecedentes de cirugía vaginal previa. De ellas, 7 (35\%) habían sido intervenidas mediante un procedimiento antincontinencia (Tabla 2).

El tiempo operatorio medio fue de 35 minutos (rango 30-40) y la estancia hospitalaria media de
Tabla 2. Relación de cirugía vaginal previa.

\begin{tabular}{lc}
\hline Procedimiento & n (\%) \\
\hline Colporrafia anterior & $13(56,5)$ \\
Burch & $6(26)$ \\
Agentes injectables & $1(4,3)$ \\
Ninguno & $3(13,2)$ \\
\hline
\end{tabular}

1,8 días (rango 1-3). No se presentaron casos de retención urinaria. Tampoco se observaron complicaciones mayores del tipo de exposición del injerto, infección, sangrado o dispareunia. Dos de las pacientes fueron perdidas para el seguimiento. Si bien, en las visitas correspondientes a los 6 y 12 meses seguían ambas continentes. Consecuentemente, sólo 23 pacientes de las pacientes fueron seguidas 72 meses y consideradas para evaluar resultados de continencia.

$\mathrm{El}$ pad test preoperatorio demostró incontinencia leve en $4(17,3 \%)$, moderada en $15(65,2 \%)$ y severa en $4(17,3 \%)$ pacientes. Usando el pad test para evaluar objetivamente las pacientes después de 6 meses, 20 (87\%) mujeres estaban completamente secas, 2 (87\%) mejoraron y 1 $(4,3 \%)$ permaneció incontinente. Sin embargo, después de 72 meses, 15 (65,2\%) permanecieron secas, $3(13 \%)$ mejoraron y $5(21,7 \%)$ estaban incontinentes (Tabla 3).

Tabla 3. Resultados acordes con pad test durante el estudio.

\begin{tabular}{lccc}
\hline Pad test & $\begin{array}{c}\text { Preoperatorio } \\
\text { N (\%) }\end{array}$ & $\begin{array}{c}\text { 6 mes } \\
\text { N (\%) }\end{array}$ & $\begin{array}{c}\text { 72 meses } \\
\text { N (\%) }\end{array}$ \\
\hline Leve (1-10g) & $4(17,3)$ & $2(8,6)$ & $3(13)$ \\
Moderado (11-50g) & $15(65,2)$ & - & $2(8,6)$ \\
Severo (>50g) & $4(17,3)$ & $1(4)$ & $3(13)$ \\
\hline
\end{tabular}

\section{DISCUSION}

En la literatura científica han sido publicados la utilización de una amplia gama de materiales para la creación de slings: fascia autóloga y heteróloga, xenoinjerto y sintéticos. Dentro de los últimos, las mayas de polipropileno ha sido el material que mejores resultados a corto plazo ha conseguido a la hora de realizar un sling pubovaginal $^{9}$. 
La mejora en los biomateriales, simplicidad y eficacia en bandas libres de tensión en los últimos 10 años han contribuido al amplio uso de sling mediouretral minimamente invasivos. Se ha postulado que el soporte uretral influye en la IUE sin determinar cuán alta o baja está la uretra, sino cómo es soportada. Incrementos simulados en la presión abdominal comprimen la uretra contra el soporte natural que incluye fascias y la pared vaginal, siendo un factor importante en la coaptación uretral ${ }^{1}$.

El soporte uretral depende principalmente de la fijación de los tejidos parauretrales al arco tendineo y a la pared pélvica. El objetivo de la técnica TUS es la reconstrucción anatómica de este soporte. Además, como el espacio retropúbico es preservado no es necesaria la citoscopia, lo que permite ahorrar tiempo y coste económico. El TUS no distorsiona la anatomía normal. Por lo que, la fase de vaciado miccional no se compromete, tal como se ha comprobado clínicamente en nuestro estudio en la que ninguna de las pacientes presentó retención urinaria.

Nuestros resultados están de acuerdo con lo publicado en $1999^{11}$. Inicialmente, la técnica TUS fue realizada con pericardio bovino. A pesar de los buenos resultados iníciales, hubo una tasa inaceptable de extrusión después de 6 meses de seguimiento. Este problema fue confirmado después por otros autores en un ensayo clínico en el que llegaron a presentar un 90\% de complicaciones postoperatorias relacionadas al uso de sling de pericardio bovino ${ }^{11}$. Desde entonces, el SIS ha sido utilizado para la realización del TUS.

Este xenoinjerto está compuesto de una matriz extracelular que después de su implantación emerge en el tejido huésped y es reemplazado por las propias fibras de colágeno. El SIS es remodelado por el tejido receptor y no produce fibrosis generalizada. Estudios preclinicos han demostrado que, cuando se compara con injertos sintéticos, este biomaterial muestra mayor resistencia a la infección bacteriana. La explicación, probablemente, se debe a la rápida vascularización que ocurre inmediatamente después de su implantación. La razón para el uso de este material en el soporte suburetral es producir un soporte a largo plazo que permita la corrección de la hipermobilidad uretral y mejorar la coaptación al mismo tiempo ${ }^{14}$. Se cree que el biomaterial implantado remodela el tejido dentro del tejido natural y es responsable para la formación del soporte suburetral con elasticidad y flexibilidad que provee un soporte mas anatómico y fisiológico. Sin embargo, este mecanismo aun no es entendido completamente ${ }^{14}$.

En este estudio, no hubo casos de infección, exposición del material implantado, retención urinaria post operatoria, fibrosis vaginal o dispareunia. Los pacientes no tuvieron síntomas del tracto urinario bajo. Sin embargo, se observa que algunas pacientes que fueron inicialmente continentes llegaron a ser incontinentes durante el seguimiento. Una de las razones para explicar estos fallos con el tiempo fue el uso de SIS de primera generación, ya que no tenía tratamiento específico para retardar el proceso de remodelamiento.

Recientemente procedimientos similares han sido reportados sin complicaciones y una eficacia similar a corto plazo $^{3,15}$.

\section{CONCLUSIÓN}

Los resultados de este estudio preliminar indican que $\mathrm{El}$ TUS es una opción razonable $\mathrm{y}$ segura para tratar mujeres con IUE. El procedimiento no distorsiona la anatomía normal, por lo que no se evidenció disfunción del vaciamiento en este estudio. Estudios adicionales usando materiales y dispositivos diferentes se están desarrollando para tratar de conocer el papel que puede jugar este concepto en el armamentario del cirujano.

\section{REFERENCIAS}

1. Pétros, P, Ulstem U (1993) An integral theory and its method for the diagnosis and management of female urinary incontinence. Scand J Urol Nephrol Suppl. 1993;153:1-93.

2. Ulmsten U, Henriksson L, Johnson P, Varhos G (1996) An ambulatory surgical procedure under local anesthesia for treatment of female urinary incontinence. Int Urogynecol $\mathrm{J}$ Pelvic Floor Dysfunct.1996;7(2):81-85.

3. Petros PE, Richardson P. Midurethral Tissue Fixation System sling - a micromethod for cure of stress incontinence-preliminary report. Aust N Z J Obstet Gynaecol. 2005;45 (5):372-375.

4. Palma P, Riccetto C, Dambros M, Fraga R. Pre pubic sparc: A promising alternative for selected cases of USI. Revista Urología Panamericana 2003; 15(3):19-21.

5. Delorme E. Transobturator urethral suspension: mini-invasive procedure in the treatment of stress urinary incontinence in women. Prog Urol. 2001; 11(6):1306-1313. 
6. Palma P, Riccetto C, Herrmann V, Dambros M, Thiel M, Bandiera S, Netto NR. Transobturator SAFYRE sling is as effective as the transvaginal procedure. Int Urogynecol $\mathrm{J}$ Pelvic Floor Dysfunct. 2005; 16(6):487-491.

7. Blaivas JG, Appell RA, Fantl JA, Leach G, McGuire EJ, Resnick NM, Raz S, Wein AJ. Standards of efficacy for evaluation of treatment outcomes in urinary incontinence: recommendations of the Urodynamic Society. Neurourol Urodyn. 1997; 16(3):145-147.

8. McGuire EJ, Fitzpatrick CC, Wan J, Bloom D, Sanvordenker J, Ritchey M, Gormley EA. Clinical assessment of Urethral Sphincter Function. J Urol. 1993;150(5Pt1):14521454.

9. Norris JP, Breslin DS, Staskin DR. Use of synthetic material in sling surgery: a minimally invasive approach $\mathrm{J}$ Endourol. 1996;10(3):227-30.

10. Palma PCR) "Sling" tendineovaginal de pericárdio bovino. Experiência inicial. J.Bras Ginec. 1999;109:93-97.

11. Martucci RC, Ambrogini A, Calado AA, Zerati M, Muller MEA Pubovaginal sling with bovine pericardium for treatment of stress urinary incontinence. Braz J Urol. 2000; 26:208-214.
12. Palma PC, Riccetto CLZ, Herrmann V, Dambros M, Mesquita R, Netto NRJr Tendinous vaginal support (T.V.S.) using the porcine small intestine submucosa (SIS): a promising anatomical approach for urinary stress incontinence. J Urol. 2001;165:5(A)

13. Iosif CS. Porcine corium sling in the treatment of urinary stress incontinence.. Arch Gynecol. 1987;240(3):131-136.

14. Palma PCR, Dambros M, Riccetto CLZ, Hermann V, Netto Jr., N R(2001) Pubovaginal sling using the porcine small intestine submucosa for stress urinary incontinence. Braz J Urol. 27:483-488.

15. Foglia G, Mistrangelo E, Lijoi D, Alessandri F, Ragni N. Transfacial vaginal tape for surgical treatment of stress urinary incontinence. Urology. 2006;68(2):423-426.

Correspondencia autor: Dr. P. Palma

División de Urología Feminina. Universidad eStadual de Campinas. UNICAMP, Campinas. Sao Paulo, Brasil.

E-mail autor: ppalma@uol.com.br

Información artículo: Original - Incontinencia femenina

Trabajo recibido: abril 2007

Trabajo aceptado: mayo 2007 